\title{
Patterns of Medication Use among Children in Households Enrolled in the Aid to Families with Dependent Children Program
}

\author{
THOMAS R. SHARPE ${ }^{(11)}$ AND MICKEY C. SMITH ${ }^{(11)}$ \\ Research Institute of Pharmaceutical Sciences, School of Pharmacy, University of Mississippi, University, Mississippi, \\ USA [T.R.S.] and Department of Health Care Administration, School of Pharmacy, University of Mississippi, \\ University, Mississippi, USA [M.C.S.]
}

\begin{abstract}
Summary
This study examined patterns of medication use among children in 791 families, in two counties in Mississippi, which had children enrolled in the Aid to Families with Dependent Children (AFDC) program. One-twelfth of the interviews were conducted each month via household interviews. Interviews were completed in $\mathbf{5 4 0}$ households containing 1616 children ( $48.8 \%$ male, $80.9 \%$ black). Thirteen percent had taken at least one prescription drug and $21.5 \%$ had taken at least one over-the-counter (OTC) drug in the previous 2 wk. Analgesics (29.4\%), cough/cold remedies (19.2\%), vitamins $(15.7 \%)$, and anti-infectives $(12.4 \%)$ accounted for three-fourths of the instances of drug use. Over three-fourths $(76.4 \%)$ of the prescriptions were new and $61.2 \%$ were paid for by Medicaid. Approximately three-fifths (62.7\%) of OTC medicine uses were with medications already on hand. For prescription medications the physician was the soure of information on use in $87.7 \%$ of uses. For OTC use, the comparable percentage was 24.6.
\end{abstract}

\section{Abbreviations}

AFDC, aid to families with dependent children

FY, fiscal year

OTC, over-the-counter

Starfield (10) noted that "knowledge about the distribution of health problems in the population... cannot be derived from experiences in medical centers." She argues that knowledge about the distribution and extent of medical problems among children cannot be obtained from studies in facilities, but rather from population-based studies. Knowledge about medical care for children outside the institutional setting is sparse indeed, and the information concerning patterns of medication use is even more limited.

Child Health Surveys have been conducted for some time by investigators at the University of Rochester, who noted that the quality of data on medication use among children "leaves much to be desired" (9). They report that the Kaiser Research Center (Portland, OR) collects such data, but that the data suffer from methodologic problems. The International Collaborative Study conducted under WHO auspices collected data on medicine use by age of the patient, but presents little information that describes the special needs of children (2).

The present study focuses on a special group of Medicaideligible children, who reside in a rural area. Davis (1) pointed out that, "rural residents receive few benefits from the Medicaid program." Her statement is supported by data from Mississippi, which show that only slightly more than $30 \%$ of AFDC children eligible for Medicaid services actually receive such services (44,$355 / 143,028$ in FY 1980) (3). What are the reasons for the nonrecipient status of the remainder? What are the experiences of the former? These are questions for which the literature provides incomplete answers.

The Rochester studies indicated that medication use by children is related to socioeconomic class, family income, health insurance coverage, and access to medical care (5). Relevant to our study population of Medicaid recipients is the fact that in 1975 they found that children covered by Medicaid were likely to receive fewer acute care medicines and fewer vitamins and tonics than their non-Medicaid counterparts (9). In an earlier report they had found that although $90 \%$ of the eligible child population were enrolled in the Medicaid program patterns of care after implementation of Medicaid changed little (6).

The only other study that we found relating specifically to Medicaid drug use by children discussed prescription of tetracyclines for children under the age of eight years (4). Among its findings, this study reports that such prescribing (which is contraindicated) is significantly more prevalent in rural practice

Data are available from other studies on medication use by children, but the Medicaid population is not specifically identified. One investigation from our own research group is represented in this category. We conducted interviews in 1200 households in 1976 (8). From these interviews, 470 symptomatic episodes were reported, using a 6-month reporting period, for children aged 17 years and younger. In 38\% of these episodes no medical care was obtained in response to symptoms. OTC drugs were used to treat the symptoms in $11 \%$ of the cases.

More disconcerting than the lack of knowledge about use of medication among children is the observation that despite the central role medications play in medical care, there seems to be a general lack of interest (at least from a research perspective) regarding such use.

Silver (7) recently completed a comprehensive review of the current literature in maternal and child health, which has incorporated into a Congressionally mandated study by the Select Panel for the Promotion of Child Health. The findings of this Panel, released in early 1981 in a four volume report, excluded drugs and pharmaceutic services from the statistical profiles of the Panel report. Similarly, medications were not examined in the background paper and were omitted from consideration among the "Research and Data Needs" described in Volume I. Finally, medications were not included in the "Recommendations for Selected Federal Programs."

This lack of understanding and interest concerning children's patterns of medication use was the stimulus for the present study. Its focus is on both prescription and OTC medication use among children in AFDC households. The AFDC population was selected because it is generally accepted that this group faces a greater number of problems concerning access to medical care. Specifically, the objectives included the following:

1. To determine the frequency of prescription and OTC medication use among children in AFDC households. 
2. To describe patterns of medication use, by therapeutic category, among children in these households.

3. To examine the mechanisms used by these households to obtain prescription and OTC medications.

4. To identify sources of drug information used by these households.

\section{METHODS}

The sample consisted of the 791 families, residing in Lee and Calhoun Counties in Mississippi, which had children enrolled in the AFDC program in January, 1980. Lee County offers two population groups: those residing in Tupelo, a city of some 25,000 and a medical center for Northeast Mississippi, and those residing in the county surrounding the city. Calhoun County is relatively isolated, medically speaking, with the largest town, Bruce, having a population of fewer than 2000 .

Names and addresses of those eligible were obtained from the respective Chancery Clerk offices of the two counties, where such information is a matter of public record. Recipients were then systematically assigned to one of the twelve months for which data were collected so that one-twelfth of the interviews were conducted each month (February, 1980-January, 1981). During each month, households that were lost through AFDC program attrition were replaced by a random sample of recipients who had been added to the AFDC rolls since January, 1980. This included 106 household replacements during the data collection period.

Data were collected via a household interview questionnaire. Trained personnel interviewed the head of the household (usually the mother) or other responsible adult living in the house. The respondents answered questions regarding their own attitudes, health status, and use of services, as well as questions concerning the health status and use of services by children living in the household.

The household interviews were quite extensive. Questions pertained to: demographic characteristics, availability of transportation, use of attitude toward medical and pharmacy services, availability of health insurance and other third-party payment resources, current health status and behavior, anxiety, availability of and access to medical and pharmacy services, and purchase and use of prescription and non-prescription medications. The results presented in this report are based on data analysis from the portions of the interview that focused on the use of medication and pharmacy services by the AFDC children.

\section{RESULTS}

A total of 791 household interviews were originally scheduled of which 55 households contained more than one AFDC family. When this occurred, data were collected concerning both families during the same interview. This process resulted in a total of 736 AFDC households scheduled for interview. Among those 736 interviews, 196 (26.6\%) were not completed. Most frequent reasons for not obtaining an interview: nobody at home after three attempted contacts $(85 ; 11.5 \%)$, respondent moved $(43 ; 5.8 \%)$, and interviewer could not locate respondent household $(42 ; 5.7 \%)$. Only $19(2.6 \%)$ persons refused to be interviewed or terminated the interview before it was completed.

The 1616 children in the 540 respondent households included 789 (48.8\%) males and 827 (51.2\%) females. Approximately fourfifths $(80.9 \%)$ of the children were black. The median age was 8.5 years, and the ages ranged from newborn to 17 years.

Respondents were asked about drug use by the children within the previous $2 \mathrm{wk}$. It was reported that $210(13.0 \%)$ had taken at least one prescription drug and $348(21.5 \%)$ had taken at least one OTC drug in that period. Among children who did consume a prescription medication, reports were that $131(8.1 \%)$ had used one prescription medication, 62 (3.8\%) had consumed two, and 15 $(1.0 \%)$ had taken three or more prescription drugs. OTC medications were consumed somewhat more frequently, although 1280 (79.2\%) of these children were reported not to have used any OTC medications during the previous 2 wk. Reports were that 283
(17.5) of the AFDC children has used one OTC drug, 43 (2.7\%) had taken two such medications and $10(0.6 \%)$ had consumed three OTC medications in the previous 2 wk. No child was reported to have consumed more than three OTC medications during that period.

Table 1 depicts the distribution of drug use, by therapeutic category, for the 708 prescription and OTC drugs, which were consumed by these children. Analgesics $(208 ; 29.4 \%)$ cough/cold remedies $(136 ; 19.2 \%)$, vitamins $(111 ; 15.7 \%)$ and anti-infectives $(88 ; 12.4 \%)$ accounted for three-quarters of the instances of drug use.

Respondents were also asked to indicate how and where they obtained their prescription and OTC medications. Among the 309 prescription medication uses by the respondent children, 236 (76.4\%) were the result of a new prescription written by the physician and $40(12.9 \%)$ were refills in which the patient or family member visited the pharmacy. Few prescription drug uses resulted from a telephone communication to the pharmacy, by either the physician or patient, and in only three $(1.0 \%)$ instances was the medication already on hand. Samples from the physician's office accounted for $1.7 \%$ of the instances of prescription drug use

A large proportion $(189 ; 61.2 \%)$ indicated that the Medicaid program was the payment source for their prescription medications. It was found that $95(30.7 \%)$ of the prescription medications were purchased by cash or check. These findings are consistent with responses that $1242(76.7 \%)$ of the children were eligible for prescription drugs under Medicaid.

In contrast to the prescription medications, a majority $(250$ $62.7 \%$ ) of OTC medicine use was with medications that were already on hand. With few exceptions, the remainder $(126 ; 31.6 \%)$ was purchased for the specific illness episode.

Table 1. Drug use by major categories

\begin{tabular}{|c|c|c|c|}
\hline $\begin{array}{l}\text { Selected drugs and } \\
\text { drug classes }\end{array}$ & $\begin{array}{l}\text { Prescription } \\
\text { drugs number } \\
(\%) n=309\end{array}$ & $\begin{array}{c}\text { OTC }^{1} \text { drugs } \\
\text { number }(\%) \\
n=399\end{array}$ & $\begin{array}{c}\text { Total drugs } \\
\text { number }(\%) \\
n=708\end{array}$ \\
\hline Analgesics & $7(2.3 \%)$ & $201(50.4 \%)$ & $208(29.4 \%)$ \\
\hline Tylenol & & $82(20.6 \%)$ & $82(11.6 \%)$ \\
\hline St. Joseph aspirin & & $37(9.3 \%)$ & $37(5.2 \%)$ \\
\hline Bayer aspirin & & $35(8.8 \%)$ & $35(4.9 \%)$ \\
\hline Anacin & & $17(4.3 \%)$ & $17(2.4 \%)$ \\
\hline Narcotics & $7(2.3 \%)$ & & $7(1.0 \%)$ \\
\hline $\begin{array}{l}\text { Cough/cold } \\
\text { remedies }\end{array}$ & $75(24.3 \%)$ & $61(15.3 \%)$ & $136(19.2 \%)$ \\
\hline Robitussin & $14(4.5 \%)$ & $5(1.3 \%)$ & $19(2.7 \%)$ \\
\hline Creomulsion & & $14(3.5 \%)$ & $14(2.0 \%)$ \\
\hline Benylin & $12(3.9 \%)$ & & $12(1.7 \%)$ \\
\hline Dimetapp & $11(3.6 \%)$ & & $11(1.6 \%)$ \\
\hline Dimetane & $10(3.2 \%)$ & & $10(1.4 \%)$ \\
\hline Vitamins & $11(3.6 \%)$ & $100(25.1 \%)$ & $111(15.7 \%)$ \\
\hline Flintstones & & $50(12.5 \%)$ & $50(7.1 \%)$ \\
\hline One-A-Day & & $13(3.3 \%)$ & $13(1.8 \%)$ \\
\hline Anti-infectives & $87(28.2 \%)$ & $1(0.3 \%)$ & $88(12.4 \%)$ \\
\hline Generic ampicillin & $21(6.8 \%)$ & & $21(3.0 \%)$ \\
\hline Keflex & $13(4.2 \%)$ & & $13(1.8 \%)$ \\
\hline Hematinics & $19(6.1 \%)$ & $8(2.0 \%)$ & $27(3.8 \%)$ \\
\hline $\begin{array}{l}\text { Ferrous sulfate } \\
\text { (generic) }\end{array}$ & $10(3.2 \%)$ & $4(1.0 \%)$ & $14(2.0 \%)$ \\
\hline Antihistimines & $21(6.8 \%)$ & 0 & $21(3.0 \%)$ \\
\hline Oral contraceptives & $12(3.9 \%)$ & 0 & $12(1.7 \%)$ \\
\hline All other & $77(23.9 \%)$ & $28(7.0 \%)$ & $105(14.8 \%)$ \\
\hline
\end{tabular}

\footnotetext{
${ }^{1}$ OTC, over-the-counter
} 
Table 2. "How did you learn what this drug was used for?"

\begin{tabular}{lcc}
\hline \multicolumn{1}{c}{ Source of knowledge } & $\begin{array}{c}\text { Prescription medi- } \\
\text { cations frequency } \\
(\%)(n=309)\end{array}$ & $\begin{array}{c}\text { OTC }{ }^{1} \text { medications } \\
\text { frequency }(\%) \\
(n=399)\end{array}$ \\
\hline Physician & $271(87.7 \%)$ & $98(24.6 \%)$ \\
Nurse & $5(1.6 \%)$ & $10(2.5 \%)$ \\
Pharmacist & $5(1.6 \%)$ & $8(2.0 \%)$ \\
Someone else & $3(1.0 \%)$ & $41(10.3 \%)$ \\
Have used drug for a long time & $0(0.0 \%)$ & $127(31.8 \%)$ \\
Labeling & $7(2.3 \%)$ & $34(8.5 \%)$ \\
Television or other media & $0(0.0 \%)$ & $54(13.5 \%)$ \\
Other & $5(1.6 \%)$ & $19(4.8 \%)$ \\
Don't know or no answer & $13(4.2 \%)$ & $8(2.0 \%)$ \\
\hline
\end{tabular}

${ }^{1}$ OTC, over-the-counter.

Approximately one-third $(135 ; 33.8 \%)$ of the OTC medications were purchased at a pharmacy. Most of the others were purchased at either a grocery $(150 ; 37.6 \%)$ or at a discount store $(83 ; 20.8 \%)$. This use of non-pharmacy sources for OTC medications may be related to the rural location of the households and subsequent longer average distance to pharmacy. Roughly half of the households patronized a pharmacy more than 3 miles from their home for the prescription and/or OTC drugs, and more than $12 \%$ of the households were located 10 or more miles from their regular pharmacy.

Finally, respondents were asked to indicate "how did you learn what this drug is used for?" Results, shown in Table 2, indicate that for prescription medications, $271(87.7 \%)$ indicated the physician. For OTC medications, respondents indicated that longstanding use of the medication $(127 ; 31.8 \%)$, the physician $(98$; $24.6 \%$ ), television or other media $(54 ; 13.5 \%)$, someone other than physician, nurse or pharmacist $(14 ; 10.3 \%)$, and labeling $(34,8.5 \%)$ were the most frequent sources of this information.

\section{DISCUSSION}

The data gathered in this study do not indicate a high level of medication use in the sample, which consisted of "welfare" children. In a 2-wk period only one of eight received a prescription medication, and about one of five received an OTC medication.
Nevertheless, this translates on the average to three prescription and five OTC medication uses per year, per child.

Clearly, from these statistics and from such other data as are availiable, children - welfare or not-account for a substantial amount of drug use in this country. Just as clearly, medication is an important part of the therapy of these individuals. In view of this finding, it is somewhat surprising to note the relative lack of data on medication use by children. Lacking these data it is difficult to put the results of the present study into any form of context. There are few data with which to compare them, and this in itself argues for further research. When research on medication use by children becomes more widespread it may be possible to make judgments concerning both the universality of the present findings and the appropriateness of the medication use.

\section{REFERENCES AND NOTES}

1. Davis, K.: Medicaid payments and utilization of medical services by the poor. Inquiry, 13: 122 (1976).

2. Kohn, Robert and White, Kerr L., Eds.: Health Care, an International Study. pp. 223-277 (Oxford University Press, London, 1976).

3. Mississippi Medicaid Commission, Twelfth Annual Report. p. 12 (Jackson, MS 1981).

4. Ray, W. A., Federspiel, C. F., and Schaffner, W.: Prescribing of tetracycline to children less than 8 years old. J. Am. Med. Assoc., 237: 2069 (1970).

5. Roghmann, K. L. J.: The use of medications: a neglected aspect of health and illness behavior. In: R.J. Haggarty, K.J. Roghmann and I.B. Press, Eds.: Child Health and the Community. (John Wiley, New York, 1975).

6. Roghmann, K. J., Hagarty, R. J., and Lorenz, R.: Anticipated and actual effects of Medicaid on the medical care pattern of children. N. Engl. J. Med., 285: 1053 (1971).

7. Select Panel for the Promotion of Child Health: Better Health for Our Children A National Stategy, Vol. I-IV. (DHHS, Washington, D.C., 1981).

8. Smith, M. C.: Health needs survey: Final Report Submitted to Northeast Mississippi Health Planning Council. (University of Mississippi, University, MS 1976).

9. Sorenson, A. A. and Roghmann, K. J.: Use of over-the-counter and prescription drugs among pre-school children. Paper presented at the American Public Health Association Annual Meeting, Miami Beach, October (1976).

10. Starfield, B.: Patients and populations: necessary links between the two ap proaches to pediatric research. Pediatr. Res., 15: 1 (1981)

11. Requests for reprints should be addressed to either author. School of Pharmacy, University, MS 38677.

12. This research was supported by Maternal and Child Health Research Gran \#MC-R-280438 and by the Research Institute of Pharmaceutical Sciences, University of Mississippi.

13. Received for publication May 4, 1982.

14. Accepted for publication November 4, 1982. 